\title{
PROCESSO DE EMPODERAMENTO FEMININO MEDIADO PELA QUALIFICAÇÃO PARA O TRABALHO NA CONSTRUÇÃO CIVIL
}

\author{
Female empowerment process mediated through qualification to work on civil construction \\ El proceso de empoderamiento femenino mediado por la calificación para el trabajo en \\ la construcción civil
}

Maria Celeste Landerdahl ${ }^{1} \quad$ Letícia Becker Vieira ${ }^{2} \quad$ Laura Ferreira Cortes ${ }^{3} \quad$ Stela Maris de Mello Padoin ${ }^{4}$

\begin{abstract}
RESUMO
Pesquisa qualitativa, exploratório-descritiva que objetivou conhecer as repercussões do Programa de Extensão Universitária Mulheres Conquistando Cidadania no cotidiano de mulheres participantes. Foi desenvolvida em um município do interior do Rio Grande do Sul/Brasil. Participaram do estudo 13 mulheres egressas do Programa referido. As entrevistas semiestruturadas foram realizadas nos meses de janeiro a agosto/2011. Da análise de conteúdo temática destacou-se a categoria: processo de empoderamento a partir da participação no Programa Mulheres Conquistando Cidadania. Identificaram-se a construção de confiança, a mudança significativa na postura e o modo de pensar das mulheres em relação a sua autopercepção, conhecimento e poder de decisão. Constataram-se transformações na forma de pensar os papéis sociais de mulheres e homens a partir de referenciais de cidadania e empoderamento. Conclui-se que tal experiência, tanto no que se refere à Extensão quanto à presente pesquisa, constitui-se uma temática atual e necessária na área de saúde da mulher.
\end{abstract}

Palavras-chave: Enfermagem. Saúde da mulher. Empoderamento. Trabalho feminino.

\begin{abstract}
Qualitative research, exploratory-descriptive study which aimed to know the repercussions of the University Extension Program of Women Gaining Citizenship in the daily life of participant women. It was developed in an inland town of Rio Grande do Sul, Brazil. There were 13 women that participated in the study which were egresses from the Program involved. The semi-structured interviews were carried out from January to August 2011. The thematic content analysis stood out the category: empowerment process from the participation in the Women Gaining Citizenship Program. It was identified the construction of confidence, significant change in attitude and thinking of women in relation to their self-perception, knowledge and power of decision. They expressed changes in the way of thinking at the social roles of women and men, from references of citizenship and empowerment. It's concluded that such experience, as much as regards the Extension as the current study, constitutes a necessary and current issues in the women's health area.
\end{abstract}

Keywords: Nursing. Women's health. Empowerment. Women work.

\section{Resumen}

Investigación cualitativa, exploratoria-descriptiva que tuvo por objetivo conocer las repercusiones del Programa de Extensión Universitaria Mujeres Ganando Ciudadanía en la vida cotidiana de las mujeres participantes. Fue desarrollada en una ciudad del interior de Rio Grande do Sul, Brasil. Participaron del estudio 13 mujeres egresadas del programa. Las entrevistas semiestructuradas se llevaron a cabo de enero a agosto/2011. El análisis de contenido temático destacó la categoría: proceso de empoderamiento a partir de la participación de las mujeres en el Programa Mujeres Ganando Ciudadanía. Se identificó la construcción de la confianza, un cambio significativo en la actitud y en el pensamiento de la mujer en relación a la percepción de sí misma, conocimiento y poder de decisión. Mostraron transformaciones en la forma de pensar acerca de los papeles sociales de mujeres y hombres a partir de los puntos de referencia de ciudadanía y empoderamiento. Se concluye que esta experiencia, desde lo que respecta a la Extensión hasta el estudio actual, constituye un tema actual y necesario en el área de salud de la mujer.

Palabras clave: Enfermería. Salud de la Mujer. Empoderamiento. Trabajo de mujeres.

\footnotetext{
${ }^{1}$ Enfermeira. Doutoranda pelo DINTER UNIFESP/SP - UFSM/RS - UFRJ/RJ. Professora adjunta do Departamento de Enfermagem UFSM/RS. Líder do Núcleo de Estudos Mulheres, Gênero e Políticas Públicas - NEMGeP do Dep. Enfermagem - UFSM-RS. E-mail: mclanderdahl@gmail.com; ${ }^{2}$ Enfermeira. Especialista em Gênero e Sexualidade IMS/UERJ. Mestre em Enfermagem. Doutoranda na Escola de Enfermagem Anna Nery (EEAN) da Universidade Federal do Rio de Janeiro - EEAN - UFRJ/RJ. Estudante do Núcleo de pesquisa de Saúde da Mulher NUPESM-EEAN/UFRJ. Bolsista CNPq. Vice-líder do Núcleo de Estudos Mulheres, Gênero e Políticas Públicas - NEMGeP do Departamento de Enfermagem - UFSM/RS e do Grupo de Pesquisa Cuidado à Saúde das Pessoas, Familias e SociedadePEFAS- UFSM-RS . E-mail: lebvieira@hotmail.com; ${ }^{3}$ Enfermeira. Especialista pela Residência Multiprofissional - UFSM/RS. Mestranda pelo PPGEnf - UFSM/RS. Membro do Núcleo de Estudos Mulheres, Gênero e Políticas Públicas - NEMGeP do Departamento de Enfermagem - UFSM/RS e do Grupo de Pesquisa Cuidado à Saúde das Pessoas, Famílias e Sociedade - PEFAS - UFSM-RS. E-mail: Iferreiracortes@gmail.com; Enfermeira. Doutora em Enfermagem pela EEAN/UFRJ. Professora adjunta do Departamento de Enfermagem UFSM/RS. Líder do GP-PEFAS - UFSM/RS. E-mail: stelamaris_padoin@hotmail.com
} 


\section{INTRODUÇÃO}

0 uso da categoria gênero, entendida a partir de elementos que integram relações sociais elaboradas histórica e culturalmente entre mulheres e homens, tem sido estimulado e expandido em estudos acadêmicos da área da saúde. Uma vez articulada a outros determinantes sociais, tem se mostrado fundamental para a compreensão de processos de saúde e adoecimento de indivíduos e comunidades ${ }^{1}$.

Neste sentido, existem situações de vulnerabilidade na vida das mulheres, que as tornam mais ou menos susceptíveis a morbidades relacionadas não só com fatores biológicos mas também com situações de discriminação. Nessa esteira, as desigualdades de gênero geram déficit de poder de decisão sobre a vida e corpo das mulheres; divisão sexual injusta de tarefas e de lazeres, definindo, muitas vezes, oportunidades e formas de inserção de mulheres e homens no trabalho².

Tal compreensão tem possibilitado avanços na condução de políticas públicas dirigidas às mulheres nas últimas décadas no Brasil, tendo em vista a emergência em superar visões reducionistas. 0 desafio maior está em abordar as mulheres de forma ampla, considerando sua autonomia em vários aspectos, dentre eles o financeiro, como quesito fundamental para promoção de seu bem-estar e saúde. Alguns pressupostos nesta linha estão expressos na atual Política Nacional de Atenção Integral à Saúde da Mulher - PNAISM² que, articulada ao Plano Nacional de Políticas Públicas para as Mulheres - PNPM³, recomenda iniciativas e ações que promovam o empoderamento feminino, entendendo que este contribui na mudança das estruturas e dinâmicas sociais que reproduzem a posição subalterna das mulheres no mundo ${ }^{4}$, fazendo frente, portanto, às desigualdades de gênero.

Neste lastro, entende-se que gênero, ao dialogar com empoderamento feminino, tem possibilitado reflexões e debates acerca da inserção da mulher no mundo do trabalho, originando outro elemento importante na análise dos determinantes sociais da saúde - 0 trabalho. Esse, visto como atividade que medeia as relações do sujeito com o mundo, seja pela produção de objetos ou serviços, ou como instrumento de socialização e construção de cidadania, é um importante fator de produção de subjetividade.

As relações de trabalho são, também, marcadas por desigualdades de gênero, que operam criando uma divisão sexual do trabalho. É neste espaço que se fortalecem cotidianamente os desníveis de poder entre mulheres e homens, seja por meio da determinação de tarefas diferenciadas ou pela desqualificação, financeira ou simbólica, das tarefas realizadas pelas mulheres ${ }^{5}$.

Embora na vigência destes e outros obstáculos, a participação das mulheres no mercado de trabalho representa fonte de riqueza econômica para o país, além de evidenciar a "tendência de decréscimo do hiato de gênero"6:151. Assim, se faz necessário superar as dificuldades que persistem para a inclusão e permanência das mulheres no mercado de trabalho nas mesmas condições que os homens ${ }^{7}$.

0 movimento atual de transformações sociais e econômicas tem contribuído para um panorama de mudanças nas relações de trabalho e na inserção social das mulheres, que quase interferem na divisão sexual do trabalho. É o caso da entrada de mulheres trabalhadoras em atividade tradicionalmente reservada aos homens.

São essas mulheres, inseridas nestes cenários laborais, que por vezes procuram os serviços públicos de saúde onde atuam os profissionais de Enfermagem. Mulheres que apresentam problemas e queixas que, embora afeitas à dimensão biológica, têm sua origem no conflito gerado para compatibilizar papéis sociais ligados ao espaço doméstico eà maternidade, com aqueles relacionados ao trabalho remunerado.

É urgente, portanto, que os profissionais que trabalham neste campo, transcendam o previsível biológico aplicado na atenção à saúde das mulheres posto que, promover a cidadania feminina é, também, promover saúde. É preciso "deslocar o olhar e a escuta dos profissionais de saúde da doença para os sujeitos em sua potência de criação da própria vida, objetivando a produção de coeficientes crescentes de autonomia durante o processo do cuidado à saúde" $8: 746$.

A vivência com estas mulheres em uma Unidade Básica de Saúde, cujas condições sociais e de escolaridade agravam em demasia sua falta de autonomia financeira, inspirou a realização de um programa de extensão universitária, o qual teve como objetivo principal contribuir na implementação do PNPM. Esse plano foi elaborado pela Secretaria de Políticas para as Mulheres - SPM e tem sido concretizado com várias iniciativas, dentre as quais a qualificação profissional de mulheres. Como um dos eixos de intervenção tem-se: a autonomia econômica e igualdade no mundo do trabalho e cidadania, considerando as dimensões étnico-raciais, geracionais, regionais e de deficiência, a fim de promover a igualdade de gênero nas relações de trabalho ${ }^{3}$.

Esta iniciativa foi desenvolvida pelo Núcleo de Estudos Mulheres, Gênero e Políticas Públicas, do Departamento de Enfermagem da Universidade Federal de Santa Maria. Para tanto, foi utilizada a extensão universitária como recurso que possibilita transformar a realidade dos indivíduos, na medida em que os instrumentaliza para serem sujeitos de sua própria transformação e do meio social onde vivem.

O Programa de Extensão Universitária (PROEXT 2009) Mulheres Conquistando Cidadania, foi implementado em 2010 equalificou 38 mulheres do município de Santa Maria, interior do Rio Grande do Sul, para o trabalho na construção civil.

Na sua finalização, mais do que conjugar pesquisa à extensão, era primordial para a equipe executora conhecer as repercussões do Programa Mulheres Conquistando Cidadania no cotidiano de mulheres participantes, sendo esse o objetivo deste estudo. 


\section{MÉTODO}

0 presente estudo de caráter exploratório e descritivo, mediante abordagem qualitativa, foi desenvolvido com mulheres egressas do Programa. Esta abordagem permitiu compreender o universo de significados, motivos, crenças, valores e atitudes de indivíduos, o que corresponde a um espaço mais profundo das relações humanas ${ }^{9}$.

0 programa foi desenvolvido em dois eixos: técnico e político. 0 primeiro com 70 horas foi ministrado pelo Serviço Nacional de Aprendizagem Industrial - SENAI, através de cursos de assentamento de cerâmica e pintura predial interna e externa. 0 segundo, de 30 horas, foi efetivado por meio de oficinas de saúde e cidadania e compartilhado entre discentes de graduação dos Cursos de Enfermagem, Psicologia, Pedagogia, Serviço Social e Comunicação; enfermeiras da rede pública de saúde; bem como alunas de pós-graduação e docentes do Curso de Enfermagem da UFSM. Ambos os eixos foram implementados de forma concomitante, tornando possível problematizar o cotidiano de vida das mulheres e conteúdos das aulas práticas, possibilitando a troca de saberes.

Participaram da pesquisa 13 mulheres egressas do Programa, que foram contactadas por telefone. Mediante aceitação, foram realizadas entrevistas individuais. 0 critério de inclusão foi ter participado do Programa. A coleta procedeu no período de janeiro-agosto de 2011 em uma unidade básica. Neste local, o Curso de Enfermagem da UFSM desenvolve atividades de ensino, pesquisa e extensão, sendo desta região a maioria das mulheres participantes.

Para a produção dos dados utilizou-se a entrevista semiestruturada, composta por perguntas abertas, permitindo às respondentes discorrer sobre o tema proposto, sem respostas ou condições prefixadas pelas pesquisadoras ${ }^{9}$. Contemplou questionamentos que versavam sobre a participação das mulheres no programa em foco, em especial a vivência nas oficinas. A média de duração das entrevistas foi de 20 minutos, e o fechamento amostral foi definido pela saturação teórica a partir da convergência dos achados ao objetivo proposto no estudo ${ }^{10}$.

As informações foram gravadas e transcritas para posterior análise de conteúdo temática, que se constituiu de três etapas: ordenação, classificação dos dados e análise final ${ }^{9}$. Foram identificadas as ideias centrais e aspectos relevantes acerca da vivência das mulheres no Programa, no intuito de construir categorias empíricas. Para análise final, foi articulado o material estruturado ao referencial teórico, visando à identificação do conteúdo subjacente ao manifestado, na tentativa de responder à questão da pesquisa?.

Os aspectos éticos que envolvem investigação com seres humanos, Resolução 196/96, foram respeitados durante todo o trâmite da pesquisa e o projeto obteve aprovação do Comitê de Ética em Pesquisa da UFSM sob CAEE: 23081.011791/ 2010-26. Para a manutenção do sigilo e anonimato, nas falas das participantes, foi utilizado um código com a letra M (mulher) e numeral ordinário em ordem crescente

\section{RESULTADOS}

Das entrevistadas cinco tinham idade entre 20 e 30 anos; uma entre 30 e 40 anos; cinco entre 40 e 50 anos e, duas entre 50 e 60 anos. Em relação ao estado civil, quatro mulheres eram solteiras; quatro mantinham relação estável com companheiro; três mulheres casadas; uma divorciada e, igualmente, uma mulher viúva.

Quanto à raça, cinco mulheres declararam-se negras, e igualmente, cinco declararam-se brancas, três declararam-se pardas. Quanto à ocupação laboral no início do Programa, seis mulheres encontravam-se em situação de desemprego; duas tinham como ocupação o trabalho de empregada doméstica; duas trabalhavam na área de serviços gerais em empresas; duas mulheres trabalhavam na confecção de doces e/ou salgados e uma trabalhava como cabeleireira. Do total das mulheres entrevistadas apenas duas mantinham trabalho formal com carteira assinada. Vale destacar que, logo após o término do curso, cinco mulheres estavam se inserindo no trabalho na construção civil.

Na análise, foi marcante o uso da expressão "eu posso", evidenciando que os conhecimentos adquiridos, tanto nas oficinas de saúde e cidadania, como nas aulas teórico-práticas do SENAI, possibilitaram outro olhar sobre si mesmas. Estas observações foram cristalizadas no conteúdo de suas falas e na sua postura segura a respeito daquilo que desejam para si. Dados que, aliados a outros, encaminharam para a categoria intitulada processo de empoderamento a partir da qualificação para o trabalho. Considerando a riqueza das falas, procurou-se construir subcategorias que expressam algumas especificidades afeitas à categoria-mãe.

"Eu vi que posso o que quero, e vou conseguir".

As marcas do conhecimento conferido pelo Programa repercutiram de forma visível, na sua autopercepção e poder de decisão.

Agora eu me vejo uma mulher; antes eu não entendia nada, não sabia nada (...), ficava só em casa, fazendo faxina, agora eu me vejo uma mulher que tem capacidade de fazer alguma coisa (M1).

Antes eu era uma pessoa medrosa, tinha medos, tinha vontade de fazer, mas que sempre me vinha àquelas palavras: ah tu não pode, tu é mulher! Isso é coisa de homem! Depois do curso eu vi que posso o que quero, e vou conseguir. Então mudei bastante meu modo de pensar, meu modo de fazer as coisas. 
Muita coisa mudou para mim e para melhor! Estou mais forte mais decidida! (M5).

O curso foi maravilhoso, no sentido que posso tanto quanto qualquer homem. Eu posso tudo que eu quero e posso conseguir, pois estou capacitada (M6).

Estou começando a ficar mais livre, para ir trabalhar, para me cuidar, tenho mais tempo agora para mim! Tenho o meu dinheiro. Eu me sinto muito mais empoderada! 0 curso foi muito importante para mim porque eu me senti mais, mais mulher, mais tudo, podendo fazer, podendo me ajudar e ajudar os outros (M9).

"Ou trabalho com cerâmica ou trabalho com pintura, não me assusto mais"

Além disso, a capacitação para o mercado de trabalho tornou-as mais confiantes para uma possível inserção na área da construção civil, repercutindo na forma de se verem como força de trabalho valorizado.

Não tenho medo de procurar emprego como eu tinha antes. Agora tenho pelo menos uma esperança de trabalhar na construção civil, e antes nem isso eu tinha (M12).

Aprendi aqui que a mulher tem que se cuidar, tem que se valorizar, porque como tem mulher com depressão e coisa por aí, e não se valorizam nada. Depois do curso, fiquei mais calma, mais equilibrada, porque, não adianta, a situação de desemprego ataca os nervos, mas agora, ou trabalho com cerâmica ou trabalho com pintura, então não me assusto mais como me assustava antes (M13).

"A mulher pode tanto quanto o homem".

Identifica-se na fala dessas mulheres também uma mudança na forma de pensar os papéis sociais femininos e masculinos, determinada a partir da participação no Programa. Mostram-se informadas sobre seus direitos para trabalhar na construção civil e remetem à importância da igualdade de gênero nos vários âmbitos da vida social.

Somos capazes de fazer as coisas, independente de ser serviço de homem, serviço de mulher, independente de cuidar de filho, independente de pintar uma parede, assentar uma cerâmica, a gente pode! É só ter força de vontade, muitas podem não ter estrutura ou corpo de um homem, mas isso não ébarreira (M2).

Foi muito bom falar sobre cidadania; até então eu não sabia o que era ser um cidadão, o que era cidadania, o que a gente tem de direito e dever. Temos que procurar esses direitos. Eu evoluí, foi muito interessante. Temos que ser iguais (M3).

Fui tratada que o homem podia mais que a mulher, mas agora vejo que não, que a mulher pode tanto quanto o homem. Ou seja, eles não podem mais do que elas, podem tanto quanto. Precisamos disso para viver melhor (M5).

Nós não podemos ser desvalorizadas, nós temos que trabalhar lado a lado, em condições iguais, de formas iguais, somos iguais (M10).

\section{DISCUSSÃO}

Os resultados desta investigação conduziram a análise no sentido de se reconhecer o empoderamento como um processo que poderá ser do âmbito individual e/ou coletivo, que possibilita tomada de decisões que influenciam nos dois âmbitos. Assim, foi possível perceber o desenvolvimento da capacidade crítico-reflexiva das mulheres para olhar a realidade onde vivem, trabalham e se relacionam. Essa postura que pode movê-las em busca daquilo que desejam, como donas de sua vida, na medida em que consigam entender e fazer diante de uma cultura cuja estrutura ainda as submete a posições de subalternidade.

Destacam-se os núcleos de sentido: posso tanto quanto qualquer homem, estou capacitada, eu posso, somos iguais, somos capazes. As falas das mulheres estão marcadas por expressões de valorização, confiança, poder de decidir sobre sua vida, igualdade de direitos, superação, desafios, que parecem repercutir de forma positiva no seu cotidiano pessoal e profissional. Todas representam algo que parece emergir como substrato fundamental para seu empoderamento.

0 termo empoderamento, na tradução brasileira, ou empowerment, na língua inglesa, tem raízes na segunda metade do século XX, em lutas pelos direitos civis, por meio da bandeira do movimento negro e movimento feminista ${ }^{12-14}$. Esta categoria de análise é conhecida e estudada em muitos países, porém, no Brasil, essas reflexões são incipientes. Consiste em uma alternativa para estudos no campo da exclusão e marginalidade, sendo uma estratégia para romper com paradigmas tradicionais de atenção e intervenção ${ }^{15}$.

0 empoderamento feminino, na visão de feministas, compreende a alteração radical dos processos e estruturas que reduzem a posição de subordinação das mulheres. As mulheres tornam-se empoderadas por meio da tomada de decisões 
coletivas e de mudanças individuais ${ }^{14} .0$ empoderamento "não pode ser fornecido nem tampouco realizado para pessoas ou grupos, mas se realiza em processos em que esses se empoderam a si mesmos". Por meio desse processo é possível que as pessoas renunciaem a situações de tutela, impotência e dependência, assumindo assim a direção de sua própria vida ${ }^{12: 3}$.

Na promoção da saúde o empoderamento vem sendo abordado em duas vertentes: o psicológico e o social ou comunitário, também chamado de coletivo. 0 primeiro é definido como um maior controle sobre a própria vida, que as pessoas sentem por meio do sentimento de pertencer a grupos, o que pode ocorrer sem a participação em ações coletivas. Está apoiado em vertente filosófica individualista, com a tendência de ignorar a influência de fatores estruturais e sociais. Chamase a atenção para a possibilidade de esse tipo de empoderamento se transformar em atitudes e discursos vazios, uma vez que não discute as raízes dos problemas, tampouco busca alternativas ao que está estabelecido ${ }^{13}$.

Já, no empoderamento comunitário, observa-se a presença de fatores situados em distintas esferas da vida social. Estão presentes microfatores integrados ao plano individual, a exemplo do desenvolvimento da autoconfiança e da autoestima; na mesosfera social, encontramos estruturas de mediação nas quais os membros de um coletivo compartilham conhecimentos e ampliam a sua consciência crítica; ao nível macro de fatores há estruturas sociais como o estado e a macroeconomia ${ }^{13}$.

Pode-se pensar, assim, que o empoderamento psicológico e a realidade estrutural vivida fazem parte do empoderamento comunitário. Deve-se buscar apoiar pessoas e coletivos a realizarem suas próprias análises para que tomem as decisões que considerem corretas, desenvolvendo a consciência crítica e a capacidade de intervenção sobre a realidade ${ }^{13}$. Neste sentido, profissionais ou agentes externos podem mediar e concretizar ações, auxiliar e oferecer subsídios para a criação de espaços que favoreçam e sustentem processos de empoderamento, em especial o feminino, os quais refletem situações de ruptura e de mudança do curso de vida ${ }^{12}$. Foi pautado nesses pressupostos que se delineou o Programa e que as falas das mulheres denotam o despertar do processo de empoderamento no seu cotidiano de vida.

Este processo envolve práticas não tradicionais de aprendizagem e ensino que desenvolvam uma consciência crítica. No empoderamento, processo e produto se entrelaçam, sendo interferidos pelo contexto ecológico e social. Os resultados não são somente metas concretas, mas sim conhecimentos, sentimentos, motivações ${ }^{13}$.

Ao que parece, as participantes apontam que o desenvolvimento do Programa Mulheres Conquistando Cidadania contribuiu significativamente para a construção de um pensar crítico diante de uma sociedade desigual e onde as mulheres ainda ocupam posição de subalternidade em relação aos homens no mundo do trabalho. Isto é manifestado nos depoimentos que denotam a apropriação das mulheres acerca do conhecimento, dos papéis tradicionais de gênero, das suas vidas e possibilidades de trabalho.

Percebe-se que, para as mulheres, a construção do processo de empoderamento partiu da dimensão psicológica, uma vez que, mencionaram questões relacionadas à autoimagem e autopercepção, tais como a possibilidade de autocuidado, de valorização e da realização enquanto mulheres e cidadãs. Além disso, houve a percepção de fortalecimento e empoderamento sobre seus direitos, bem como a perspectiva de inserção no trabalho, mesmo reconhecendo as barreiras inscritas em concepções culturais e sociais, como machismo, preconceito e discriminação.

Acredita-se que o empoderamento feminino seja um processo norteado por parâmetros tais como: construção de uma autoimagem e confiança positiva; desenvolvimento da habilidade para pensar criticamente; a construção da coesão de grupo; a promoção da tomada de decisões; e ação ${ }^{14}$. Para tanto, esta construção acontece por meio de níveis de igualdade, quais sejam: bem-estar; acesso aos recursos; conscientização; participação e controle social. Estes aspectos compõem a dimensão psicológica do processo de empoderamento. Referem-se ao desenvolvimento do autorreconhecimento, por meio do qual as pessoas adquirem ou fortalecem seu sentimento de poder, competência, autovalorização e autoestima. A dimensão política implica na transformação das estruturas sociais visando à redistribuição de poder, a fim de produzir mudanças nas estruturas de organização social ${ }^{12}$.

Em relação ao desenvolvimento da habilidade para pensar criticamente, as mulheres elucidam nas falas a mudança no pensar e fazer, nas concepções em relação aos atributos femininos e masculinos, bem como na busca pelos direitos e por igualdade. Elas atribuem esta mudança ao conhecimento sobre os direitos, as políticas públicas, as legislações trabalhistas entre outros temas que foram apreendidos nas oficinas de cidadania.

Ressalta-se que, com a realização das oficinas, foi possível problematizar o cotidiano de vida das mulheres e a sociedade essencialmente patriarcal. A igualdade entre mulheres e homens também se fez presente nos depoimentos, que demonstram a compreensão de que as mulheres devem ser valorizadas e estar lado a lado com os homens. Outro aspecto positivo nas falas foi a identificação entre as mulheres cursistas com vistas à composição de um grupo. Aponta-se, assim, para a construção da coesão de grupo permeado por relações de amizade, empatia, solidariedade e aprendizado mútuo, que permaneceu após o término do curso e está presente no cotidiano de suas relações sociais.

Sobre a promoção da tomada de decisões, as respondentes demonstram a mudança de comportamento diante da busca pelos direitos de escolha e trabalho enquanto mulheres e a ação de estarem se inserindo no mercado de trabalho, a que muitas não tinham acesso. 
No contexto familiar, além das implicações para os filhos e outros membros da família, a noção de igualdade e de empoderamento permitiu reflexões e mudanças de comportamento também dos companheiros. Essas mudanças são cristalizadas em postura de incentivo e valorização de suas companheiras, o que mostra que o apoio familiar é fundamental. Pais, maridos e filhos, na medida em que se constituem a rede social mais próxima e significativa, devem atuar como parceiros e aliados no processo de crescimento e valorização das mulheres.

0 empoderamento implica mudanças não apenas nas próprias experiências dos sujeitos, mas também nas das outras pessoas, grupos e instituições envolvidas, bem como nas políticas públicas e nas estruturas culturais. Representa um desafio às relações patriarcais, em especial dentro da família; ao poder dominante do homem e à manutenção dos seus privilégios de gênero. Significa uma mudança na dominação tradicional dos homens sobre as mulheres, garantindo a estas a autonomia no que se refere ao controle dos seus corpos, à sua sexualidade, ao seu direito de ir e vir, bem como um rechaço ao abuso físico e à violação sem castigo, ao abandono e às decisões unilaterais masculinas que afetam toda a família" ${ }^{11}$.

Vale mencionar que uma das entrevistadas demonstrouse insegura para desenvolver o trabalho na construção civil, fato compreendido em função de o processo de empoderamento ser complexo, na medida em que está relacionado com a história de cada uma e com suas características individuais, e integrar uma discussão recente e atual. Algumas características realçadas como timidez, baixa autoestima, e até mesmo medo, podem dificultar o processo de empoderamento. Pode-se se pensar, também, que a insegurança esteja alinhada a outros motivos, como a própria ideia de que a construção civil é um trabalho de homens, que exige força física, e que pode deixar as mulheres masculinizadas. Neste sentido, entende-se que "0 empoderamento exige ação no social. 0 fortalecimento do indivíduo acarreta, motiva e estimula o fortalecimento dos demais indivíduos da rede de relacionamento em situação semelhante" 11:11.

A superação das desigualdades integra vários setores sociais. A educação, com vistas à superação da cultura que submete e exclui, é fundamental para a conquista da cidadania feminina. Mulheres em condições de igualdade, também no mundo do trabalho, podem contribuir no alcance de uma sociedade mais justa e solidária.

Compreende-se que o empoderamento das mulheres é um desafio que exige esforços de toda a sociedade para o desenvolvimento de alianças e estratégias para romper com as estruturas vigentes. Neste sentido, o Programa contribuiu, mostrando-se uma oportunidade de estímulo ao empoderamento feminino na visão das mulheres participantes. Percebe-se, desta forma, a urgência da Enfermagem de se alinhar a iniciativas que contemplem ações voltadas para a melhoria da qualidade de vida, inclusão social e afirmação da cidadania ${ }^{16}$.

\section{CONSIDERAÇÕES FINAIS}

0 estudo apontou o despertar das mulheres com vistas a um processo de empoderamento. Na medida em que 0 Programa impactou positivamente no cotidiano das participantes, as marcas deixadas dizem respeito a algumas transformações na sua vida e saúde, oriundas da elevação da autoestima, da valorização e percepção de si como ser humano que tem direitos e que pode enfrentar o instituído.

Entende-se que esta experiência, tanto no que se refere à Extensão Universitária quanto à presente pesquisa, constitui uma inovação na maneira de conceber e fazer saúde, uma vez que convocou-nos a entender e abordar a saúde das mulheres na perspectiva de gênero, cidadania, trabalho e empoderamento feminino. Todos esses são fatores que fazem parte do cotidiano de vida das mulheres e que influenciam em sua saúde, devendo ser, portanto, compreendidos e abordados como inerentes ao panorama sanitário.

A oportunidade de colocar em prática uma política pública que tem como foco principal a superação de desigualdades de gênero, assim avaliar alguns aspectos desta política, foi um aprendizado relevante para estudantes e profissionais que se envolveram nos dois momentos. Reforçaramse a possibilidade e a necessidade de fazer pesquisa a partir de ações de extensão, na medida em que ambos se complementam, na busca por conhecimentos novos, que se cristalizam em novas posturas dos sujeitos. Esse cenário comprova a importância da universidade como potencial disparador de mudanças na sociedade.

Para os profissionais em constante formação, e para as mulheres, este estudo revelou a importância do Programa como um facilitador do processo de cidadania e empoderamento feminino. Ampliou-se, também, a visão acerca do contexto sociocultural das participantes e da amplitude do campo de atuação em saúde, uma vez que, comprometidas com as demandas sociais e de saúde, reforçamos a possibilidade de atuar visando à igualdade de gênero e à integralidade do cuidado.

No âmbito do ensino sugere-se que profissionais da área da saúde, em especial os da enfermagem, dirijam um olhar mais atento às demandas ditas e não ditas pelas mulheres. Que os subsídios teóricos e práticos possibilitem ao acadêmico rever conceitos, princípios e valores, que devem estar alinhados a pressupostos éticos, políticos e crítico-reflexivos, bem como ao compromisso com os preceitos do modelo de saúde em construção no Brasil. No âmbito da assistência, faz-se necessário que as usuárias se reconheçam como sujeitos com direitos, oportunidades, responsabilidades e competências na busca por autonomia nos vários aspectos de sua vida e saúde.

Recomenda-se a realização de estudos com foco em determinantes sociais da saúde com destaque aos construtos sobre empoderamento feminino, com vistas a ampliar a compreensão deste processo, ainda incipiente na literatura, e a reflexão sobre novos subsídios para a prática de enfermagem. 


\section{REFERÊNCIAS}

1. Villela W, Monteiro S. A promissora expansão do uso da categoria gênero pela Saúde Coletiva Brasileira. Ciênc. saúde coletiva. 2009 jul./ ago.; 14(4): 994.

2. Ministério da Saúde (Brasil), Secretaria de Atenção à Saúde, Departamento de Ações Programáticas Estratégicas. Política Nacional de Atenção Integral à Saúde da Mulher: princípios e diretrizes. Brasília(DF): Editora MS; 2007.

3. Ministério da Saúde (Brasil). Secretaria Especial de Políticas para as Mulheres. II Plano Nacional de Políticas para as Mulheres. Brasilia: Secretaria Especial de Políticas para as Mulheres. Brasilia (DF): Editora MS; 2008.

4. Deere CD, León, M. 0 empoderamento da mulher: direitos à terra e direitos de propriedade na América Latina. Por to Alegre(RS): Editora da UFRGS; 2002.

5. Maruani M. Emprego. In: Hirata H, Senetier D (orgs). Dicionário crítico do Feminismo. São Paulo(SP): Ed. da UNESP, 2009; p. 85-90.

6. Alves JED, Corrêa S. Igualdade e desigualdade de gênero no Brasil: um panorama preliminar, 15 anos depois do Cairo. Seminário Brasil, 15 anos após a Conferência do Cairo. [citado em 10 jan 2012]. Belo Horizonte (MG); 2009. Disponível em: <http://www.abep.nepo.unicamp.br/docs/ outraspub/cairo15/Cairo15_3alvescorrea.pdf>.

7. Abramo LW. A inserção da mulher no mercado de trabalho: uma força de trabalho secundária? [tese]. São Paulo (SP): Programa de Doutorado em Sociologia, Universidade de São Paulo; 2007.

8. Campos GW, Barros RB, Castro AM. Avaliação da Política Nacional de Promoção da Saúde. Ciênc. saúde coletiva. 2004 jul./sep.; 9(3): 745-9.

9. Minayo MCS. 0 desafio do conhecimento: pesquisa qualitativa em saúde. 12. ed. São Paulo(SP): HUCITEC; 2010.

10. Fontanella BJB, Ricas J, Turato ER. Amostragem por saturação em pesquisas qualitativas em saúde: contribuiç̃̃es teóricas. Cad. saúde pública. 2008 jan.; 24(1): 17-27.

11. Sousa RMBC, Melo MCOL. Mulheres na gerência em tecnologia da informação: análise de expressões de empoderamento. Revista Gestão USP. 2009 jan./mar.; 16(1): 1-16.

12. Kleba ME. Empoderamento: processo de fortalecimento dos sujeitos nos espaços de participação social e democratização política. Saúde soc. 2009; 18(4): 733-43.

13. Carvalho SR. Os múltiplos sentidos da categoria "empowerment" no projeto de Promoção à Saúde. Cad. saúde pública. 2004 jul./ago.; 20(4): 1088-95

14. Costa AAA. Gênero, poder e empoderamento das mulheres. [citado em 2012 jan. 10]. Disponível em: <http://www.agende.org.br/docs/File/ dados_pesquisas/feminismo/Empoderamento\%20\%20Ana\%20Alice.pdf>.
15. Mager M. Empowerment: o conceito e as implicações na aplicação prática. In: Müller VR, Morelli AJ. Crianças e adolescentes: a arte de sobreviver. Maringá(PR): EDUEM; 2002. p.133-52.

16. Silva KL, Sena, RR, Grillo MJC, Horta NC. Formação do enfermeiro: desafios para a promoção da saúde. Esc. Anna Nery Rev. Enferm. 2010 abr.jun.: 14(2): 368-76.

\section{NOTA}

Demais colaboradoras do manuscrito:Bruna Dedavid da Rocha, Daiane da Silva Prates, Karine Jacques Hentges, Mariana Resener de Moraise Paola Curcio Dalla Pozza 